\title{
Prediksi Pesediaan Stock Pulsa Menggunakan Fuzzy Linear Regresion
}

\author{
Misdiyanto \\ Fakultas Teknik, Universitas Panca Marga Probolinggo \\ Jl. Yos Sudarso Pabean Dringu No. 107, Probolinggo, 6721 \\ Telp : (0335) 422715, Fax : (0335) 427923 \\ E-mail : misdie@upm.ac.id
}

\begin{abstract}
Electronic phone credit (pulsa) sales at this time showed an outstanding increase, because of the needs of phone credit usage every day by the society that has now became a need. Phone credit business will never stop because human always communicate with one another. To ensure the availability of the product in the phone credit server, the phone credit server manager routinely, in a particular period, inventorize the purchase of phone credit products. From the exploration above, the market conditions in a business are always changing, In a business. Process prediction is important for every business person in decision-making. Then, there is a need to build a prediction system that could predict phone credit transactions in the next period. Results or output of this system is predictive value of transactions in the next period with average error value of $4 \%$ using $\beta 1=0,5$ and $\beta 2=0,2$. Therefore, it can be used as a reference for the management in the decisionmaking.
\end{abstract}

Keywords : prediction, pulse stock, Fuzzy, liner regresion

\begin{abstract}
Abstrak
Penjualan pulsa secara elektronik saat ini menunjukkan kenaikan yang luar biasa, dikarenakan adanya kebutuhan pemakaian pulsa setiap hari oleh masyarakat yang sekarang telah menjadi kebutuhan. Bisnis pulsa tidak akan berhenti selama manusia masih berkomunikasi dengan yang lain. Untuk menjaga ketersediaan produk dalam server pulsa agar tetap ada, sebagai pengelola server pulsa secara rutin, dalam periode tertentu, melakukan investasi deposit pembelian produk pulsa. Dari pemaparan diatas kondisi permintaan pasar yang senantiasa berubah-ubah di dalam sebuah kegiatan bisnis, maka proses prediksi merupakan hal penting bagi setiap pelaku bisnis dalam pengambilan keputusan manajemen untuk mengadaptasikan dengan kondisi yang ada. Maka perlu dibangun sebuah sistem prediksi yang dapat memprediksi transaksi pulsa pada periode berikutnya. Hasil atau output dari sistem ini adalah berupa nilai prediksi transaksi pada periode selanjutnya dengan tingkat rata-rata eror $4 \%$ dengan nilai $\beta 1=0,5$ dan $\beta 2=0,2$. Sehingga bisa digunakan sebagai acuan bagi pihak management dalam pengambilan keputusan.
\end{abstract}

Kata Kunci : prediksi, stock pulsa, Fuzzy, Linear Regresion

\section{PENDAHULUAN}

Penjualan pulsa secara elektronik saat ini menunjukkan kenaikan yang luar biasa, dikarenakan adanya kebutuhan pemakaian pulsa setiap hari oleh masyarakat yang sekarang telah menjadi kebutuhan. Sistem penjualan pulsa secara elektronik memudahkan konsumen untuk memperoleh pulsa dengan cepat dan tepat. Untuk menjaga ketersediaan produk dalam server pulsa agar tetap ada, sebagai pengelola server pulsa secara rutin, dalam periode tertentu, 
melakukan investasi deposit pembelian produk pulsa. Dalam menentukan jumlah biaya investasi untuk setiap produk operator tersebut tergantung bagaimana kondisi banyak sedikitnya permintaan pasar terhadap masingmasing produk. Sedangkan kondisi permintaan dan penawaran pasar senantiasa berubah -ubah setiap waktu.

Dari pemaparan diatas kondisi permintaan pasar yang senantiasa berubahubah didalam sebuah kegiatan bisnis, maka proses prediksi merupakan hal penting bagi setiap pelaku bisnis dalam pengambilan keputusan manajemen untuk mengadaptasikan dengan kondisi yang ada. Prediksi (forecasting) adalah kegiatan mengestimasi apa yang akan terjadi dimasa akan datang. Metode forecasting akan membantu dalam mengadakan pendekatan analisa terhadap tingkah laku atau pola dari data yang telah lalu, sehingga dapat memberikan cara pemikiran, pemecahan serta memberikan tingakat keyakinan yang lebih besar atas ketepatan prediksi yang dibuat. Hasil prediksi (forecasting) akan digunakan sebagai dasar menentukan besarnya deposit yang harus dilakukan untuk setiap produk telekomunikasi yang akan disediakan oleh Server Pulsa tersebut.

\section{METODOLOGI PENELITIAN}

Penelitian terdahulu dilakukan Aliyeh Kazemia. Tujuan dari penelitiannya adalah untuk mengembangkan prediksi model dari kebutuhan energi dari sektor industri di Iran. Paper ini mengusulkan sebuah model dimana Fuzzy Linier Regresion multi-level masukan untuk memprediksi tingkat akhir yang diperoleh dari tingkat awal. Dari data yang sebenarnya 1994-2008 yang digunakan untuk mengembangkan kemampuan dan Fuzzy Linear Regresi multi-level menggambarkan pendekatan dalam hal ini. Selanjutnya FLR digunakan untuk memprediksi permintaan industry dari tahun 2011 - 2020. Tujuan dari analisa regresi ini adalah untuk menemukan model matematika yang tepat dan untuk menentukan koefisien terbaik dari model data yang diberikan. Fuzzy Linear Regression sering diterapkan untuk berbagai aplikasi termasuk pemasaran, manajemen dan prediksi penjualan [1].

Penelitian selanjutnya dilakukan oleh Xiaodan Yua. Memprediksi penjualan memiliki implikasi penting untuk seleksi waktu masa depan. metode untuk memprediksi penjualan dapat diklasifikasikan menjadi tiga wilayah penelitian, yaitu riset operasi, statistik dan data pertambangan, Studi disebagian besar riset operasi tuntutan konsumen dipahami sebagai suatu variabel acak mengikuti distribusi tertentu. Tujuan Support Vector Regression (SVR) adalah untuk menemukan sebuah fungsi $\mathrm{g}(\mathrm{x})$ cocok kesemua masukan data dengan kesalahan yang paling banyak dan pada saat yang bersamaan dengan menjadi rata [2].

Penelitian yang lain dilakukan oleh Z. Ismail, A. Yahya dari Malaysia tentang memprediksi harga emas untuk periode satu bulan ke depan. Dalam penelitian ini peneliti mengusulkan pengembangan model peramalan untuk 
memprediksi harga emas kedepan mengguanakan Multiple Linear Regresion (MLR). Data yang digunakan pada penelitian ini adalah harga emas London. Banyak faktor yang menentukan harga emas dan berdasarkan para ahli. Beberapa faktor ekonomi telah diidentifikasi memiliki pengaruh pada harga emas. Variabel seperti Komoditi Biro Penelitian Indeks masa depan (CRB); USD / Euro Devisa Rate (EUROUSD); Tingkat inflasi (INF); Uang Beredar (M1); Bursa Efek New York (NYSE); Standard and Poor 500 (SPX); Treasury Bill (T-BILL) dan indeks Dollar AS (USDX) yang dianggap memiliki pengaruh pada harga. Faktorfaktor ini digunakan sebagai variabel independen dalam model Linear Regresi [3].

Logika Fuzzy pertama kali diperkenalkan oleh Prof. Lotfi A Zadeh pada tahun 1965. Ada dua pendekatan utama dalam pengembangan model regresi Fuzzy, yaitu Fuzzy Linear Regresion (FLR) dan Fuzzy Least Squares Regresion (FLSR) Fuzzy Linear Regresion pertama kali diperkenalkan oleh Tanaka pada tahun 1982. Regresi Fuzzy mengestimasi batasan yang mungkin, dikenal sebagai fungsi keanggotaan (membership function). Fungsi keanggotaan didefinisikan untuk koefisien dari variabel bebas.

\section{HASIL DAN PEMBAHASAN}

Berdasarkan penelitian yang dilakukan di CV. Metrocellular Probolinggo, ditemukan beberapa masalah yang dihadapi seperti:

a) Dalam transaksi pulsa dibutuhkan kecepatan transaksi dan ketersediaannya stock. Jika stock habis maka akan berakibat kepada pelayanan yang kurang maksimal.

b) Penentuan Purchase order ke supplier menjadi kendala dikarenakan tidak mengetahui perkiraan transaksi yang akan terjadi. Sehingga sering terjadi kekurangan stock.

Dalam penelitian ini, akan menerapkan sebuah sistem prediksi yang nantinya dapat membantu pihak manager dalam mengambil kebijakan untuk menentukan keputusan

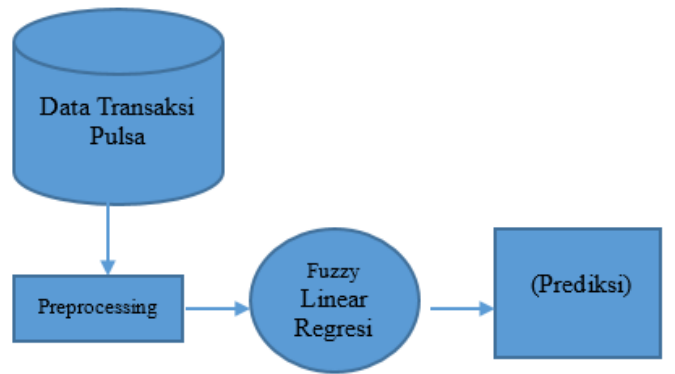

Gambar 1. Arsitektur Sistem

Arsitektur sistem dimulai dari penginputan dataset awal kemudian dilakukan preprocessing selanjutnya masuk kedalam metode Fuzzy Linear Regresion. Data Transaksi berjumlah 2500 record terdiri dari data transaksi pada bulan januari 
sampai desember tahun 2015. Dari data transaksi tersebut di rekap menjadi beberapa minggu / periode menjadi 48 minggu/periode pertahun.

Pada bab ini akan dibahas desain sistem yang didasarkan pada analisa sistem, yang meliputi perencanaan algoritma dan penerapannya dalam bahasa pemograman.

a. Tahapan pertama adalah mengumpulkan data transaksi pulsa di CV. Metro celular dalam bentuk Excel.

b. Tahap kedua adalah membuat rekap data transaksi per bulan menjadi per minggu berdasarkan jenis voucher.

c. Tahap ketiga memfilter data transaksi berdasarkan jenis voucher. Dalam penelitian ini yang diambil adalah voucher telkomsel 5000. Kemudian dibuat rekap transaksi voucher telkomsel 5000 per minggu. Mulai dari minggu ke 1 sampai minggu ke 48.

d. Tahap keempat adalah melakukan proses penghitungan manual dengan menggunakan Fuzzy Linear Regresion untuk mencari nilai presiksi.

e. Tahap kelima adalah membuat aplikasi menggunakan software Delphi 7 dan MySQL sebagai database.

f. Tahap keenam adalah melakukan uji coba pada software aplikasi yang telah dibuat.

Berikutnya adalah menentukan membership function bagi masing-masing variabel yang akan digunakan :

a) Variabel jumlah transaksi dibagi menjadi 3 himpunan Fuzzy, yaitu: Sedikit, Sedang dan Banyak.

Rekap data transaksi pulsa terdiri dari data selama satu tahun di rekap per minggu, sehingga ada 48 minggu dalam 1 tahun. Adapun processing data ada tiga tahap diantaranya adalah menentukan variabel yang akan digunakan, menentukan algoritma yang akan digunakan, proses perhitungan data. Adapun field- field yang digunakan dalam dataset adalah jumlah transaksi dan hpp. Variabel yang digunakan dalam penelitian ini adalah jumlah transaksi dan HPP (Harga Pokok Pembelian), ada beberapa variabel yang dihasilkan diantaranya adalah jml trx, hpp, persediaan, sisa stock, namun dalam penelitian ini variabel yang akan digunakan hanya harga pokok dan jumlah transaksi karena variabel ini sudah cukup untuk menentukan hasil prediksi sesuai dengan dataset yang digunakan. Bentuk data dari dataset yang digunakan nampak pada Tabel 1.

Tabel 1. Dataset Transaksi Pulsa

\begin{tabular}{|c|l|l|}
\hline Minggu Ke & Jml Trx & hpp \\
\hline 1 & 2010 & 5100 \\
\hline 2 & 2035 & 5100 \\
\hline 3 & 2004 & 5100 \\
\hline
\end{tabular}

Dalam Algoritma Fuzzy Linear Regeresion yang harus diketahui lebih dulu 
adalah fungsi keanggotaan, fungsi keanggotaan ini didefinisikan untuk koefisien dari variabel bebas, adapun bentuk persamaan dari Model Fuzzy Linear Regreresion adalah $Y=\beta_{1} X_{1}+\beta_{2} X_{2}+\ldots+\beta_{n} X_{n}$, untuk menentukan nilai dari $\beta$ akan lebih mudah dipahami dengan menggunakan derajat keanggotaan, Sedangkan $\mathrm{X}_{1}$ dan $\mathrm{X}_{2}$ adalah variabel yang digunakan dalam hal ini adalah jml transaksi dan hpp. Adapun proses perhitungan prediksi dalam penelitian ini menggunakan sample nilai $\beta_{1}$ dan $\beta_{2}$ yaitu $\beta 1=0,5 ; \beta 2=0,2$.

Tabel 2. Tabel Penghitungan Nilai Prediksi

\begin{tabular}{|c|c|c|}
\hline $\mathrm{x} 1$ & $\mathrm{x} 2$ & $\mathrm{Y}$ \\
\hline 2010 & 5100 & 2025 \\
\hline 2035 & 5100 & 2038 \\
\hline 2004 & 5100 & 2022 \\
\hline 2013 & 5100 & 2026 \\
\hline 1989 & 5100 & 2014 \\
\hline
\end{tabular}

b) Akurasi Data

Dalam penelitian ini penulis menggunakan Mean Absolute Percentage Error (MAPE) untuk mengevaluasi tingkat kesalahan model peramalan. Persamaan MSE ditunjukkan oleh rumus dibawah ini.

(Fi-Xi)/Fi x100\%

Dengan :

F_i : data hasil ramalan

X_i : data aktual

Sebagai bahan uji coba pada penelitian ini yaitu data transaksi pulsa bulan januari 2015 sampai bulan desember 2015 yang sudah direkap perminggu. Hasil uji coba menggunakan $\beta 1=0,5$ dan $\beta 2=0,2$ terlihat pada Tabel.3.

Tabel 3. Tabel Penghitungan Nilai Prediksi

\begin{tabular}{|c|c|c|}
\hline Periode & Actual & Forecast \\
\hline 1 & 2010 & 2025 \\
\hline 2 & 2035 & 2038 \\
\hline 3 & 2004 & 2022 \\
\hline 4 & 2013 & 2026 \\
\hline 5 & 1989 & 2014 \\
\hline 6 & 1876 & 1978 \\
\hline 7 & 1844 & 1962 \\
\hline 8 & 1824 & 1952 \\
\hline 9 & 1809 & 1944 \\
\hline 10 & 1820 & 1970 \\
\hline
\end{tabular}

c) Penghitungan Error

Hal ini bertujuan untuk menguji keakuratan data hasil prediksi. Pada perhitungan presentasi error menggunakan Mean Absolute Percentage Error (MAPE) untuk mengevaluasi tingkat kesalahan model peramalan/prediksi. 
MAPE mengindikasi seberapa besar kesalahan dalam meramal yang dibandingkan dengan nilai nyata. Hasil perhitungan error dapat dilihat pada tabel dibawah ini :

Tabel 4. Tabel Penghitungan Error

\begin{tabular}{|c|c|c|c|}
\hline Periode & Actual & Forecast & MAPE \\
\hline 1 & 2010 & 2025 & $1 \%$ \\
\hline 2 & 2035 & 2038 & $0 \%$ \\
\hline 3 & 2004 & 2022 & $1 \%$ \\
\hline 4 & 2013 & 2026 & $1 \%$ \\
\hline 5 & 1989 & 2014 & $1 \%$ \\
\hline 6 & 1876 & 1978 & $5 \%$ \\
\hline 7 & 1844 & 1962 & $6 \%$ \\
\hline 8 & 1824 & 1952 & $7 \%$ \\
\hline 9 & 1809 & 1944 & $7 \%$ \\
\hline 10 & 1820 & 1970 & $8 \%$ \\
\hline
\end{tabular}

Dari hasil pengukuran eror menggunakan Mean Absolute Percentage Error (MAPE) diperoleh nilai rata2 eror $4 \%$.

\section{SIMPULAN}

Adapun beberapa kesimpulan yang didapatkan antara lain:

a. Sistem Prediksi menggunakan Fuzzy Linear Regression dapat menghasilkan nilai rata- rata eror $4 \%$ dengan nilai $\beta 1=0,5$ dan $\beta 2=0,2$.

b. Sistem prediksi ini memberikan kontribusi yang bermanfaat untuk tindakan antisipasi pihak management dalam menyiapkan persediaan stock pulsa.

\section{DAFTAR PUSTAKA}

[1] Aliyeh Kazemia, Amir Foroughi, Mahnaz Hosseinzadeh, 2012. A Multi-Level Fuzzy Linear Regression Model for Forecasting Industry Energy Demand of Iran. Department of Industrial Management. University of Tehran Iran

[2] Xiaodan Yua, Zhiquan Qi, Yuanmeng Zhao. 2013. Support Vector Regression for Newspaper/Magazine Sales Forcasting. Information Technology and Quantitative Management, University of Nebraska at Omaha

[3] Z. Ismail, A. Yahya. 2009. Forecasting Gold Prices Using Multiple Linear Regression Method. Department of Faculty of Science, University Technology Malaysia.

[4] Kusumadewi, Sri. 2010. Aplikasi Logika Fuzzy Untuk Pendukung Keputusan. Graha Ilmu. 